University of South Carolina

Scholar Commons

Faculty Publications

Physical Activity and Public Health

$1-31-2013$

\title{
Myths, Presumptions, and Facts About Obesity
}

\author{
Krista Casazza \\ Kevin R. Fontaine \\ Arne Astrup \\ Leann L. Birch \\ Andrew W. Brown
}

See next page for additional authors

Follow this and additional works at: https://scholarcommons.sc.edu/

sph_physical_activity_public_health_facpub

Part of the Exercise Science Commons

\section{Publication Info \\ Published in The New England Journal of Medicine, Volume 368, Issue 5, 2013, pages 446-454. (C) 2013 Massachusetts Medical Society.}

This Article is brought to you by the Physical Activity and Public Health at Scholar Commons. It has been accepted for inclusion in Faculty Publications by an authorized administrator of Scholar Commons. For more information, please contact digres@mailbox.sc.edu. 


\section{Author(s)}

Krista Casazza, Kevin R. Fontaine, Arne Astrup, Leann L. Birch, Andrew W. Brown, Michelle M. Bohan Brown, Nefertiti Durant, Gareth Dutton, E. Michael Foster, Steven B. Heymsfield, Kerry Mclver, Tapan Mehta, Nir Menachemi, P.K. Newby, Russell R. Pate, Barbara J. Rolls, Bisakha Sen, Daniel L. Smith Jr, Diana M. Thomas, and David B. Allison 


\title{
Myths, Presumptions, and Facts about Obesity
}

\author{
Krista Casazza, Ph.D., R.D., Kevin R. Fontaine, Ph.D., Arne Astrup, M.D., Ph.D., \\ Leann L. Birch, Ph.D., Andrew W. Brown, Ph.D., Michelle M. Bohan Brown, Ph.D., \\ Nefertiti Durant, M.D., M.P.H., Gareth Dutton, Ph.D., E. Michael Foster, Ph.D., \\ Steven B. Heymsfield, M.D., Kerry Mclver, M.S., Tapan Mehta, M.S., \\ Nir Menachemi, Ph.D., P.K. Newby, Sc.D., M.P.H., Russell Pate, Ph.D., \\ Barbara J. Rolls, Ph.D., Bisakha Sen, Ph.D., Daniel L. Smith, Jr., Ph.D., \\ Diana M. Thomas, Ph.D., and David B. Allison, Ph.D.
}

A BSTRACT

From the Departments of Nutrition Sciences (K.C., M.M.B.B., D.L.S., D.B.A.), Health Behavior (K.R.F.), Pediatrics (N.D.), Medicine (G.D.), Health Care Organization and Policy (E.M.F., N.M., B.S.), and Biostatistics (T.M., D.B.A.) and the School of Public Health, Office of Energetics, Nutrition Obesity Research Center (A.W.B., D.B.A.), University of Alabama at Birmingham, Birmingham; the OPUS Center and the Department of Nutrition, Exercise, and Sports, University of Copenhagen, Copenhagen (A.A.); the Departments of Development and Family Studies (L.L.B.) and Nutritional Sciences (B.J.R.), Pennsylvania State University, University Park; Pennington Biomedical Research Center, Baton Rouge, LA (S.B.H.); Children's Physical Activity Research Group, Department of Exercise Science, Arnold School of Public Health, University of South Carolina, Columbia (K.M., R.P.); the Departments of Pediatrics and Epidemiology, Program in Graduate Medical Nutrition Sciences, and Program in Gastronomy, Culinary Arts, and Wine Studies, Boston University, Boston (P.K.N.); and the Center for Quantitative Obesity Research, Montclair State University, Montclair, NJ (D.M.T.). Address reprint requests to Dr. Allison at the University of Alabama at Birmingham, Department of Biostatistics, Birmingham, AL 35294, or at dallison@uab.edu.

This article was updated on June 6, 2013, at NEJM.org.

N Engl J Med 2013;368:446-54.

DOI: 10.1056/NEJMsa1208051

Copyright (c) 2013 Massachusetts Medical Society.

\section{BACKGROUND}

Many beliefs about obesity persist in the absence of supporting scientific evidence (presumptions); some persist despite contradicting evidence (myths). The promulgation of unsupported beliefs may yield poorly informed policy decisions, inaccurate clinical and public health recommendations, and an unproductive allocation of research resources and may divert attention away from useful, evidence-based information.

\section{METHODS}

Using Internet searches of popular media and scientific literature, we identified, reviewed, and classified obesity-related myths and presumptions. We also examined facts that are well supported by evidence, with an emphasis on those that have practical implications for public health, policy, or clinical recommendations.

\section{RESULTS}

We identified seven obesity-related myths concerning the effects of small sustained increases in energy intake or expenditure, establishment of realistic goals for weight loss, rapid weight loss, weight-loss readiness, physical-education classes, breast-feeding, and energy expended during sexual activity. We also identified six presumptions about the purported effects of regularly eating breakfast, early childhood experiences, eating fruits and vegetables, weight cycling, snacking, and the built (i.e., human-made) environment. Finally, we identified nine evidence-supported facts that are relevant for the formulation of sound public health, policy, or clinical recommendations.

\section{CONCLUSIONS}

False and scientifically unsupported beliefs about obesity are pervasive in both scientific literature and the popular press. (Funded by the National Institutes of Health.) 
P ASSIONATE INTERESTS, THE HUMAN TENdency to seek explanations for observed phenomena, and everyday experience appear to contribute to strong convictions about obesity, despite the absence of supporting data. When the public, mass media, government agencies, and even academic scientists espouse unsupported beliefs, the result may be ineffective policy, unhelpful or unsafe clinical and public health recommendations, and an unproductive allocation of resources. In this article, we review some common beliefs about obesity that are not supported by scientific evidence and also provide some useful evidence-based concepts. We define myths as beliefs held to be true despite substantial refuting evidence, presumptions as beliefs held to be true for which convincing evidence does not yet confirm or disprove their truth, and facts as propositions backed by sufficient evidence to consider them empirically proved for practical purposes.

When standards for evidence are considered, it is critical to distinguish between drawing conclusions from scientific evidence and making decisions about prudent actions. Stakeholders must sometimes take action in the absence of strong scientific evidence. Yet this principle of action should not be mistaken as justification for drawing conclusions. Regardless of the urgency of public health issues, scientific principles remain unchanged. We find the language of the Federal Trade Commission to be apt: its standard for making claims is "competent and reliable scientific evidence," defined as "tests, analyses, research, studies, or other evidence . . . conducted and evaluated in an objective manner . . . using procedures generally accepted . . . to yield accurate and reliable results." 1

The scientific community recognizes that randomized experiments offer the strongest evidence for drawing causal inferences. Nevertheless, at least since the 1960s, when Sir Austin Bradford Hill spearheaded the scientific activities that led to the acceptance of the claim that smoking causes lung cancer and to his classic writing on association and causation, ${ }^{2}$ the scientific community has acknowledged that under some circumstances (i.e., when it is unethical or unfeasible to conduct a randomized study and when observed associations are not plausibly due to confounding), inferring causality in the ab- sence of data from randomized, controlled trials is necessary and appropriate. However, the fact that the appropriateness of inferring causality holds only under certain circumstances is sometimes discounted by those who are eager to garner support for a proposal in the absence of strong data from randomized studies.

Notably, the circumstances that justify drawing a conclusion of causation from nonexperimental data are rarely met in clinical and public proposals regarding obesity. It is possible to conduct randomized studies of even the most sensitive and invasive obesity procedures, as exemplified by recent articles in the Journal. Moreover, observational associations germane to the causes, treatment, and prevention of obesity are subject to substantial confounding, fraught with measurement problems, and typically small and inconsistent. ${ }^{3}$ Such observational associations are often found to differ from those later obtained by more rigorously designed studies. ${ }^{4}$ Hence, in the present discussion, we generally conclude that a proposition has been shown to be true only when it has been supported by confirmatory randomized studies. References to published studies are used sparingly herein, with a more comprehensive listing provided in the Supplementary Appendix, available with the full text of this article at NEJM.org.

\section{MYTHS}

We review seven myths about obesity, along with the refuting evidence. Table 1 provides anecdotal support that the beliefs are widely held or stated, in addition to reasons that support conjecture.

\section{SMALL SUSTAINED CHANGES IN ENERGY INTAKE OR EXPENDITURE}

Myth number 1: Small sustained changes in energy intake or expenditure will produce large, long-term weight changes.

Predictions suggesting that large changes in weight will accumulate indefinitely in response to small sustained lifestyle modifications rely on the half-century-old 3500-kcal rule, which equates a weight alteration of $1 \mathrm{lb}(0.45 \mathrm{~kg})$ to a $3500-\mathrm{kcal}$ cumulative deficit or increment. ${ }^{5,6}$ However, applying the $3500-\mathrm{kcal}$ rule to cases in which small modifications are made for long periods violates the assumptions of the original model, which 
Table 1. Seven Myths about Obesity.*

Myth

Small sustained changes in energy intake or expenditure will produce large, long-term weight changes

Setting realistic goals in obesity treatment is important because otherwise patients will become frustrated and lose less weight

Large, rapid weight loss is associated with poorer long-term weight outcomes than is slow, gradual weight loss

Assessing the stage of change or diet readiness is important in helping patients who seek weight-loss treatment

Physical-education classes in their current format play an important role in preventing or reducing childhood obesity

Breast-feeding is protective against obesity

A bout of sexual activity burns 100 to $300 \mathrm{kcal}$ for each person involved

\section{Basis of Conjecture}

National health guidelines and reputable websites advertise that large changes in weight accumulate indefinitely after small sustained daily lifestyle modifications (e.g., walking for 20 minutes or eating two additional potato chips)

According to goal-setting theory, unattainable goals impair performance and discourage goal-attaining behavior; in obesity treatment, incongruence between desired and actual weight loss is thought to undermine the patient's perceived ability to attain goals, which may lead to the discontinuation of behaviors necessary for weight loss

This notion probably emerged in reaction to the adverse effects of nutritionally insufficient very-low-calorie diets ( $<800 \mathrm{kcal}$ per day) in the 1960s; the belief has persisted, has been repeated in textbooks and recommendations from health authorities, and has been offered as a rule by dietitians

Many believe that patients who feel ready to lose weight are more likely to make the required lifestyle changes

The health benefits of physical activity of sufficient duration, frequency, and intensity are well established and include reductions in adiposity

The belief that breast-fed children are less likely to become obese has persisted for more than a century and is passionately defended

Many sources state that substantial energy is expended in typical sexual activity between two adults

* We define myths as beliefs held true despite substantial evidence refuting them. A list of articles in which these myths are espoused is provided in the Supplementary Appendix.

were derived from short-term experiments predominantly performed in men on very-low-energy diets $\left(<800 \mathrm{kcal}\right.$ per day). ${ }^{5,7}$ Recent studies have shown that individual variability affects changes in body composition in response to changes in energy intake and expenditure, ${ }^{7}$ with analyses predicting substantially smaller changes in weight (often by an order of magnitude across extended periods) than the 3500 -kcal rule does. ${ }^{5,7}$ For example, whereas the $3500-\mathrm{kcal}$ rule predicts that a person who increases daily energy expenditure by $100 \mathrm{kcal}$ by walking 1 mile $(1.6 \mathrm{~km})$ per day will lose more than $50 \mathrm{lb}(22.7 \mathrm{~kg})$ over a period of 5 years, the true weight loss is only about $10 \mathrm{lb}(4.5 \mathrm{~kg}),{ }^{6}$ assuming no compensatory increase in caloric intake, because changes in mass concomitantly alter the energy requirements of the body.

\section{SETTING REALISTIC WEIGHT-LOSS GOALS}

Myth number 2: Setting realistic goals for weight loss is important, because otherwise patients will become frustrated and lose less weight.
Although this is a reasonable hypothesis, empirical data indicate no consistent negative association between ambitious goals and program completion or weight loss. ${ }^{8}$ Indeed, several studies have shown that more ambitious goals are sometimes associated with better weight-loss outcomes (see the Supplementary Appendix). ${ }^{8}$ Furthermore, two studies showed that interventions designed to improve weight-loss outcomes by altering unrealistic goals resulted in more realistic weight-loss expectations but did not improve outcomes.

\section{RATE OF WEIGHT LOSS}

Myth number 3: Large, rapid weight loss is associated with poorer long-term weight-loss outcomes, as compared with slow, gradual weight loss.

Within weight-loss trials, more rapid and greater initial weight loss has been associated with lower body weight at the end of long-term follow-up. ${ }^{9,10}$ A meta-analysis of randomized, controlled trials that compared rapid weight loss (achieved with very-low-energy diets) with slower 
weight loss (achieved with low-energy diets i.e., 800 to $1200 \mathrm{kcal}$ per day) at the end of shortterm follow-up ( $<1 \mathrm{yr}$ ) and long-term follow-up ( $\geq 1$ year) showed that, despite the association of very-low-energy diets with significantly greater weight loss at the end of short-term follow-up ( $16.1 \%$ of body weight lost, vs. $9.7 \%$ with lowenergy diets), there was no significant difference between the very-low-energy diets and low-energy diets with respect to weight loss at the end of long-term follow-up. ${ }^{10}$ Although it is not clear why some obese persons have a greater initial weight loss than others do, a recommendation to lose weight more slowly might interfere with the ultimate success of weight-loss efforts.

\section{DIET READINESS}

Myth number 4: It is important to assess the stage of change or diet readiness in order to help patients who request weight-loss treatment.

Readiness does not predict the magnitude of weight loss or treatment adherence among persons who sign up for behavioral programs or who undergo obesity surgery. ${ }^{11}$ Five trials (involving 3910 participants; median study period, 9 months) specifically evaluated stages of change (not exclusively readiness) and showed an average weight loss of less than $1 \mathrm{~kg}$ and no conclusive evidence of sustained weight loss (see the Supplementary Appendix). The explanation may be simple people voluntarily choosing to enter weight-loss programs are, by definition, at least minimally ready to engage in the behaviors required to lose weight.

\section{IMPORTANCE OF PHYSICAL EDUCATION}

Myth number 5: Physical-education classes, in their current form, play an important role in reducing or preventing childhood obesity.

Physical education, as typically provided, has not been shown to reduce or prevent obesity. Findings in three studies that focused on expanded time in physical education ${ }^{12}$ indicated that even though there was an increase in the number of days children attended physical-education classes, the effects on body-mass index (BMI) were inconsistent across sexes and age groups. Two meta-analyses showed that even specialized school-based programs that promoted physical activity were ineffective in reducing BMI or the incidence or prevalence of obesity. ${ }^{13}$ There is almost certainly a level of physical activity (a specific combination of frequency, intensity, and duration) that would be effective in reducing or preventing obesity. Whether that level is plausibly achievable in conventional school settings is unknown, although the dose-response relationship between physical activity and weight warrants investigation in clinical trials.

\section{BREAST-FEEDING AND OBESITY}

Myth number 6: Breast-feeding is protective against obesity.

A World Health Organization (WHO) report states that persons who were breast-fed as infants are less likely to be obese later in life and that the association is "not likely to be due to publication bias or confounding." 14 Yet the WHO, using Egger's test and funnel plots, found clear evidence of publication bias in the published literature it synthesized..$^{15}$ Moreover, studies with better control for confounding (e.g., studies including within-family sibling analyses) and a randomized, controlled trial involving more than 13,000 children who were followed for more than 6 years ${ }^{16}$ provided no compelling evidence of an effect of breast-feeding on obesity. On the basis of these findings, one long-term proponent of breast-feeding for the prevention of obesity wrote that breast-feeding status "no longer appears to be a major determinant" of obesity risk ${ }^{17}$; however, he speculated that breast-feeding may yet be shown to be modestly protective, current evidence to the contrary. Although existing data indicate that breast-feeding does not have important antiobesity effects in children, it has other important potential benefits for the infant and mother and should therefore be encouraged.

\section{SEXUAL ACTIVITY AND ENERGY EXPENDITURE}

Myth number 7: A bout of sexual activity burns 100 to $300 \mathrm{kcal}$ for each participant.

The energy expenditure of sexual intercourse can be estimated by taking the product of activity intensity in metabolic equivalents (METs), ${ }^{18}$ the body weight in kilograms, and time spent. For example, a man weighing $154 \mathrm{lb}(70 \mathrm{~kg})$ would, at 3 METs, expend approximately $3.5 \mathrm{kcal}$ per minute (210 kcal per hour) during a stimulation and orgasm session. This level of expenditure is similar to that achieved by walking at a moderate pace (approximately 2.5 miles [4 km] per hour). Given that the average bout of sexual activity 
Table 2. Presumptions about Obesity.*

Presumption

Regularly eating (vs. skipping) breakfast is protective against obesity

Early childhood is the period during which we learn exercise and eating habits that influence our weight throughout life

Eating more fruits and vegetables will result in weight loss or less weight gain, regardless of whether one intentionally makes any other behavioral or environmental changes

Weight cycling (i.e., yo-yo dieting) is associated with increased mortality

Snacking contributes to weight gain and obesity

The built environment, in terms of sidewalk and park availability, influences obesity
Basis for Conjecture

Skipping breakfast purportedly leads to overeating later in the day

Weight-for-height indexes, eating behaviors, and preferences that are present in early childhood are correlated with those later in life

By eating more fruits and vegetables, a person presumably spontaneously eats less of other foods, and the resulting reduction in calories is greater than the increase in calories from the fruit and vegetables

In observational studies, mortality rates have been lower among persons with stable weight than among those with unstable weight

Snack foods are presumed to be incompletely compensated for at subsequent meals, leading to weight gain

Neighborhood-environment features may promote or inhibit physical activity, thereby affecting obesity

* We define presumptions as unproved yet commonly espoused propositions. A list of articles in which these presumptions are implied is provided in the Supplementary Appendix.

lasts about 6 minutes, ${ }^{19}$ a man in his early-tomid-30s might expend approximately $21 \mathrm{kcal}$ during sexual intercourse. Of course, he would have spent roughly one third that amount of energy just watching television, so the incremental benefit of one bout of sexual activity with respect to energy expended is plausibly on the order of $14 \mathrm{kcal}$.

\section{PRESUMPTIONS}

Just as it is important to recognize that some widely held beliefs are myths so that we may move beyond them, it is important to recognize presumptions, which are widely accepted beliefs that have neither been proved nor disproved, so that we may move forward to collect solid data to support or refute them. Instead of attempting to comprehensively describe all the data peripherally related to each of the six presumptions shown in Table 2, we describe the best evidence.

\section{VALUE OF BREAKFAST}

Presumption number 1: Regularly eating (versus skipping) breakfast is protective against obesity.

Two randomized, controlled trials that studied the outcome of eating versus skipping breakfast showed no effect on weight in the total sample. ${ }^{20}$ However, the findings in one study suggested that the effect on weight loss of being assigned to eat or skip breakfast was dependent on baseline breakfast habits. ${ }^{20}$

\section{EARLY CHILDHOOD HABITS AND WEIGHT}

Presumption number 2: Early childhood is the period in which we learn exercise and eating habits that influence our weight throughout life.

Although a person's BMI typically tracks over time (i.e., tends to be in a similar percentile range as the person ages), longitudinal genetic studies suggest that such tracking may be primarily a function of genotype rather than a persistent effect of early learning. ${ }^{21}$ No randomized, controlled clinical trials provide evidence to the contrary.

\section{VALUE OF FRUITS AND VEGETABLES}

Presumption number 3: Eating more fruits and vegetables will result in weight loss or less weight gain, regardless of whether any other changes to one's behavior or environment are made.

It is true that the consumption of fruits and vegetables has health benefits. However, when no other behavioral changes accompany increased consumption of fruits and vegetables, weight gain may occur or there may be no change in weight. ${ }^{22}$

\section{WEIGHT CYCLING AND MORTALITY}

Presumption number 4: Weight cycling (i.e., yo-yo dieting) is associated with increased mortality.

Although observational epidemiologic studies 
Table 3. Facts about Obesity."

Fact

Although genetic factors play a large role, heritability is not destiny; calculations show that moderate environmental changes can promote as much weight loss as the most efficacious pharmaceutical agents available ${ }^{26}$

Diets (i.e., reduced energy intake) very effectively reduce weight, but trying to go on a diet or recommending that someone go on a diet generally does not work well in the long-term ${ }^{27}$

Regardless of body weight or weight loss, an increased level of exercise increases health ${ }^{28}$

Physical activity or exercise in a sufficient dose aids in long-term weight maintenance ${ }^{28,29}$

Continuation of conditions that promote weight loss promotes maintenance of lower weight ${ }^{30}$

For overweight children, programs that involve the parents and the home setting promote greater weight loss or maintenance ${ }^{31}$

Provision of meals and use of meal-replacement products promote greater weight loss 32

Some pharmaceutical agents can help patients achieve clinically meaningful weight loss and maintain the reduction as long as the agents continue to be used ${ }^{33}$

In appropriate patients, bariatric surgery results in long-term weight loss and reductions in the rate of incident diabetes and mortality ${ }^{34}$

\section{Implication}

If we can identify key environmental factors and successfully influence them, we can achieve clinically significant reductions in obesity

This seemingly obvious distinction is often missed, leading to erroneous conceptions regarding possible treatments for obesity; recognizing this distinction helps our understanding that energy reduction is the ultimate dietary intervention required and approaches such as eating more vegetables or eating breakfast daily are likely to help only if they are accompanied by an overall reduction in energy intake

Exercise offers a way to mitigate the health-damaging effects of obesity, even without weight loss

Physical-activity programs are important, especially for children, but for physical activity to affect weight, there must be a substantial quantity of movement, not mere participation

Obesity is best conceptualized as a chronic condition, requiring ongoing management to maintain long-term weight loss

Programs provided only in schools or other out-of-home structured settings may be convenient or politically expedient, but programs including interventions that involve the parents and are provided at home are likely to yield better outcomes

More structure regarding meals is associated with greater weight loss, as compared with seemingly holistic programs that are based on concepts of balance, variety, and moderation

While we learn how to alter the environment and individual behaviors to prevent obesity, we can offer moderately effective treatment to obese persons

For severely obese persons, bariatric surgery can offer a life-changing, and in some cases lifesaving, treatment

* We classify the listed propositions as facts because there is sufficient evidence to consider them empirically proved.

show that weight instability or cycling is associated with increased mortality, such findings are probably due to confounding by health status. Studies of animal models do not support this epidemiologic association. ${ }^{23}$

\section{SNACKING AND WEIGHT GAIN}

Presumption number 5: Snacking contributes to weight gain and obesity.

Randomized, controlled trials do not support this presumption. ${ }^{24}$ Even observational studies have not shown a consistent association between snacking and obesity or increased BMI.

\section{BUILT ENVIRONMENT AND OBESITY}

Presumption number 6: The built environment, in terms of sidewalk and park availability, influences the incidence or prevalence of obesity.

According to a systematic review, virtually all studies showing associations between the risk of obesity and components of the built environment (e.g., parks, roads, and architecture) have been observational. ${ }^{25}$ Furthermore, these observational studies have not shown consistent associations, so no conclusions can be drawn.

\section{FACTS}

Our proposal that myths and presumptions be seen for what they are should not be mistaken as a call for nihilism. There are things we do know with reasonable confidence. Table 3 lists nine such facts and their practical implications for public health, policy, or clinical recommendations. The first two facts help establish a framework in which intervention and preventive techniques may work. The next four facts are more prescriptive, offering tools that can be conveyed 
to the public as well established. The last three facts are suited to clinical settings.

\section{M P L I C AT IO N S}

Myths and presumptions about obesity are common. Several presumptions appear to be testable, and some of them (e.g., effects of eating breakfast daily, eating more fruits and vegetables, and snacking) can be tested with standard study designs. Despite enormous efforts promoting these ideas, research often seems mired in the accrual of observational data. Many of the trials that have been completed or are in progress do not isolate the effect of the presumed influence and the findings are therefore not definitive.

Many of the myths and presumptions about obesity reflect a failure to consider the diverse aspects of energy balance, ${ }^{35}$ especially physiological compensation for changes in intake or expenditure. ${ }^{36}$ Some myths and presumptions involve an implicit assumption that there is no physiological compensation whatsoever (i.e., the 3500-kcal rule) or only minimal compensation (e.g., a reduction in snacking as a means of reducing weight). In other cases, there is an implicit assumption of overcompensation (e.g., eating breakfast daily or increasing the intake of fruits and vegetables as a means of reducing weight). Proponents of other unsupported ideas fail to consider that people burn some amount of energy even without engaging in the activity in question (e.g., increased sexual activity). In addition, interested parties do not regularly request the results from randomized, longterm studies that measure weight or adiposity as an outcome. Therefore, the presented data are rife with circumstantial evidence, and people are not informed that the existing evidence is not compelling (e.g., breakfast consumption). Furthermore, some suggested treatment or prevention strategies may work well (e.g., increasing the consumption of fruits and vegetables) but only as part of a multifaceted program for weight reduction. Yet such a strategy is often presented as though it will have effects in isolation and even among persons not participating in weight-loss programs. We must recognize that evidence that a technique is beneficial for the treatment of obesity is not necessarily evidence that it will be helpful in population-based approaches to the prevention of obesity, and vice versa.
KNOWING AND NOT KNOWING

Why do we think or claim we know things that we actually do not know? Numerous cognitive biases lead to an unintentional retention of erroneous beliefs. ${ }^{37,38}$ When media coverage about obesity is extensive, many people appear to believe some myths (e.g., rapid weight loss facilitates weight regain) simply because of repeated exposure to the claims. ${ }^{39}$ Cognitive dissonance may prevent us from abandoning ideas that are important to us, despite contradictory evidence (e.g., the idea that breast-feeding prevents obesity in children). Similarly, confirmation bias may prevent us from seeking data that might refute propositions we have already intuitively accepted as true because they seem obvious (e.g., the value of realistic weight-loss goals). Moreover, we may be swayed by persuasive yet fallacious arguments (Whately provides a classic catalogue ${ }^{40}$ ) unless we are prepared to identify them as spurious.

Fortunately, the scientific method and logical thinking offer ways to detect erroneous statements, acknowledge our uncertainty, and increase our knowledge. When presented with an alleged truth, we can pause to ask simple questions, such as, "How could someone actually know that?" Such a simple question allows one to easily recognize some beliefs as spurious (e.g., $300 \mathrm{kcal}$ is burned during sexual intercourse). Moreover, we often settle for data generated with the use of inadequate methods in situations in which inferentially stronger study designs, including quasi-experiments and true randomized experiments, are possible, as recently illustrated (see the Supplementary Appendix). In addition, eliminating the distortions of scientific information that sometimes occur with public health advocacy would reduce the propagation of misinformation.

The myths and presumptions about obesity that we have discussed are just a sampling of the numerous unsupported beliefs held by many people, including academics, regulators, and journalists, as well as the general public. Yet there are facts about obesity of which we may be reasonably certain - facts that are useful today. While we work to generate additional useful knowledge, we may in some cases justifiably move forward with hypothesized, but not proved, strategies. However, as a scientific community, 
we must always be open and honest with the public about the state of our knowledge and should rigorously evaluate unproved strategies.

The views expressed in this article are those of the authors and do not necessarily represent the official views of the National Institutes of Health.

Supported in part by a grant (P30DK056336) from the National Institutes of Health.

Dr. Astrup reports receiving payment for board membership from the Global Dairy Platform, Kraft Foods, Knowledge Institute for Beer, McDonald's Global Advisory Council, Arena Pharmaceuticals, Basic Research, Novo Nordisk, Pathway Genomics, Jenny Craig, and Vivus; receiving lecture fees from the Global Dairy Platform, Novo Nordisk, Danish Brewers Association, GlaxoSmithKline, Danish Dairy Association, International Dairy Foundation, European Dairy Foundation, and AstraZeneca; owning stock in Mobile Fitness; holding patents regarding the use of flaxseed mucilage or its active component for suppression of hunger and reduction of prospective consumption (patents EP1744772, WO2009033483-A1, EP2190303-A1, US2010261661A1, and priority applications DK001319, DK001320, S971798P, and US971827P); holding patents regarding the use of an alginate for the preparation of an aqueous dietary product for the treatment or prevention of overweight and obesity (patent WO2011063809-A1 and priority application DK070227); and holding a patent regarding a method for regulating energy balance for body-weight management (patent WO2007062663-A1 and priority application DK001710). Drs. Brown and Bohan Brown report receiving grant support from the Coca-Cola Foun- dation through their institution. Dr. Mehta reports receiving grant support from Kraft Foods. Dr. Newby reports receiving grant support from General Mills Bell Institute of Health and Nutrition. Dr. Pate reports receiving consulting fees from Kraft Foods. Dr. Rolls reports having a licensing agreement for the Volumetrics trademark with Jenny Craig. Dr. Thomas reports receiving consulting fees from Jenny Craig. Dr. Allison reports serving as an unpaid board member for the International Life Sciences Institute of North America; receiving payment for board membership from Kraft Foods; receiving consulting fees from Vivus, Ulmer and Berne, Paul, Weiss, Rifkind, Wharton, Garrison, Chandler Chicco, Arena Pharmaceuticals, Pfizer, National Cattlemen's Association, Mead Johnson Nutrition, Frontiers Foundation, Orexigen Therapeutics, and Jason Pharmaceuticals; receiving lecture fees from Porter Novelli and the Almond Board of California; receiving payment for manuscript preparation from Vivus; receiving travel reimbursement from International Life Sciences Institute of North America; receiving other support from the United Soybean Board and the Northarvest Bean Growers Association; receiving grant support through his institution from Wrigley, Kraft Foods, Coca-Cola, Vivus, Jason Pharmaceuticals, Aetna Foundation, and McNeil Nutritionals; and receiving other funding through his institution from the Coca-Cola Foundation, Coca-Cola, PepsiCo, Red Bull, World Sugar Research Organisation, Archer Daniels Midland, Mars, Eli Lilly and Company, and Merck. No other potential conflict of interest relevant to this article was reported.

Disclosure forms provided by the authors are available with the full text of this article at NEJM.org.

We thank Drs. Kyle Grimes and S. Louis Bridges for their suggestions on an earlier version of the manuscript.

\section{REFERENCES}

1. Federal Trade Commission. Dietary supplements: an advertising guide for industry. April 2001 (http://business.ftc.gov/ documents/bus09-dietary-supplementsadvertising-guide-industry\#endnotes).

2. Hill $\mathrm{AB}$. The environment and disease: association or causation? Proc R Soc Med 1965;58:295-300.

3. Taubes G. Epidemiology faces its limits. Science 1995;269:164-9.

4. Fairman KA. Why hypotheses informed by observation are often wrong: results of randomized controlled trials challenge chronic disease management strategies based on epidemiological evidence. J Manag Care Pharm 2011;17:224-31.

5. Hall KD. Predicting metabolic adaptation, body weight change, and energy intake in humans. Am J Physiol Endocrinol Metab 2010;298:E449-66.

6. Thomas DM, Martin CK, Heymsfield S, Redmon LM, Schoeller DA, Levine JA. A simple model predicting individual weight change in humans. J Biol Dyn 2011;5:579-99.

7. Thomas DM, Schoeller DA, Redman LA, Martin CK, Levine JA, Heymsfield SB. A computational model to determine energy intake during weight loss. Am J Clin Nutr 2010;92:1326-31.

8. Linde JA, Jeffery RW, Levy RL, Pronk NP, Boyle RG. Weight loss goals and treatment outcomes among overweight men and women enrolled in a weight loss trial. Int J Obes (Lond) 2005;29:1002-5.

9. Astrup A, Rossner S. Lessons from obesity management programmes: greater initial weight loss improves long-term maintenance. Obes Rev 2000;1:17-9.

10. Nackers LM, Ross KM, Perri MG. The association between rate of initial weight loss and long-term success in obesity treatment: does slow and steady win the race? Int J Behav Med 2010;17:161-7.

11. Fontaine KR, Wiersema L. Dieting readiness test fails to predict enrollment in a weight loss program. J Am Diet Assoc 1999;99:664.

12. Kriemler S, Zahner L, Schindler C, et al. Effect of school based physical activity programme (KISS) on fitness and adiposity in primary schoolchildren: cluster randomised controlled trial. BMJ 2010; 340:c785.

13. Dobbins M, De Corby K, Robeson P, Husson H, Tirilis D. School-based physical activity programs for promoting physical activity and fitness in children and adolescents aged 6-18. Cochrane Database Syst Rev 2009;1:CD007651.

14. Horta BL, Bahl R, Martinés JC, Victora CG. Evidence of the long-term effects of breastfeeding: systematic reviews and meta-analyses. Geneva: World Health Organization, 2007.

15. Casazza K, Fernandez JR, Allison DB.
Modest protective effects of breast-feeding on obesity: is the evidence truly supportive? Nutr Today 2012;47:33-8.

16. Kramer MS, Matush L, Vanilovich I, et al. Effects of prolonged and exclusive breastfeeding on child height, weight, adiposity, and blood pressure at age $6.5 \mathrm{y}$ : evidence from a large randomized trial. Am J Clin Nutr 2007;86:1717-21.

17. Gillman MW. Breastfeeding and obesity - the 2011 scorecard. Int J Epidemiol 2011;40:681-4.

18. Jetté M, Sidney K, Blümchen G. Metabolic equivalents (METS) in exercise testing, exercise prescription, and evaluation of functional capacity. Clin Cardiol 1990; 13:555-65.

19. Bohlen JG, Held JP, Sanderson MO, Patterson RP. Heart rate, rate-pressure product, and oxygen uptake during four sexual activities. Arch Intern Med 1984; 144:1745-8.

20. Schlundt DG, Hill JO, Sbrocco T, Pope-Cordle J, Sharp T. The role of breakfast in the treatment of obesity: a randomized clinical trial. Am J Clin Nutr 1992; 55:645-51.

21. Brisbois TD, Farmer AP, McCargar LJ. Early markers of adult obesity: a review. Obes Rev 2012;13:347-67.

22. Rolls BJ, Ello-Martin JA, Tohill BC. What can intervention studies tell us about the relationship between fruit and 
vegetable consumption and weight management? Nutr Rev 2004;62:1-17.

23. Vasselli JR, Weindruch R, Heymsfield $\mathrm{SB}$, et al. Intentional weight loss reduces mortality rate in a rodent model of dietary obesity. Obes Res 2005;13:693-702.

24. Whybrow S, Mayer C, Kirk TR, Mazlan N, Stubbs RJ. Effects of two weeks' mandatory snack consumption on energy intake and energy balance. Obesity (Silver Spring) 2007;15:673-85

25. Ferdinand A, Sen B, Rahurkar S, Engler S, Menachemi N. The relationship between built environments and physical activity: a systematic review. Am J Public Health 2012;102(10):e7-e13.

26. Hewitt JK. The genetics of obesity: what have genetic studies told us about the environment. Behav Genet 1997;27: 353-8.

27. Heymsfield SB. Energy intake: reduced as prescribed? Am J Clin Nutr 2011; 94:3-4.

28. Carroll S, Dudfield M. What is the relationship between exercise and metabolic abnormalities? A review of the meta- bolic syndrome. Sports Med 2004;34: 371-418.

29. Wu T, Gao X, Chen M, van Dam RM Long-term effectiveness of diet-plus-exercise interventions vs. diet-only interventions for weight loss: a meta-analysis. Obes Rev 2009;10:313-23.

30. Middleton KM, Patidar SM, Perri MG. The impact of extended care on the longterm maintenance of weight loss: a systematic review and meta-analysis. Obes Rev 2012;13:509-17.

31. McLean N, Griffin S, Toney K, Hardeman W. Family involvement in weight control, weight maintenance and weightloss interventions: a systematic review of randomised trials. Int J Obes Relat Metab Disord 2003;27:987-1005.

32. Wing RR, Jeffery RW. Food provision as a strategy to promote weight loss. Obes Res 2001;9:Suppl 4:271S-275S.

33. Wright SM, Aronne LJ. Obesity in 2010: the future of obesity medicine: where do we go from here? Nat Rev Endocrinol 2011;7:69-70.

34. Sjöström L, Lindroos A-K, Peltonen $M$, et al. Lifestyle, diabetes, and cardiovascular risk factors 10 years after bariatric surgery. N Engl J Med 2004;351:2683-93.

35. Hill JO, Wyatt HR, Peters JC. Energy balance and obesity. Circulation 2012;126: 126-32.

36. Hall KD, Heymsfield SB, Kemnitz JW, Klein S, Schoeller DA, Speakman JR. Energy balance and its components: implications for body weight regulation. Am J Clin Nutr 2012;95:989-94.

37. Lilienfeld SO, Ammirti R, Landfield K. Giving debiasing away: can psychological research on correcting cognitive errors promote human welfare? Perspect Psychol Sci 2007;4:390-8.

38. Shermer M. Why people believe weird things: pseudoscience, superstition, and other confusions of our time. 3rd ed. London: Souvenir Press, 2007.

39. Kahneman D. Thinking fast and slow. New York: Farrar, Straus and Giroux, 2011. 40. Whately R. Elements of logic. 9th ed. London: Longman, Greens, 1875. Coppright (c) 2013 Massachusetts Medical Society.

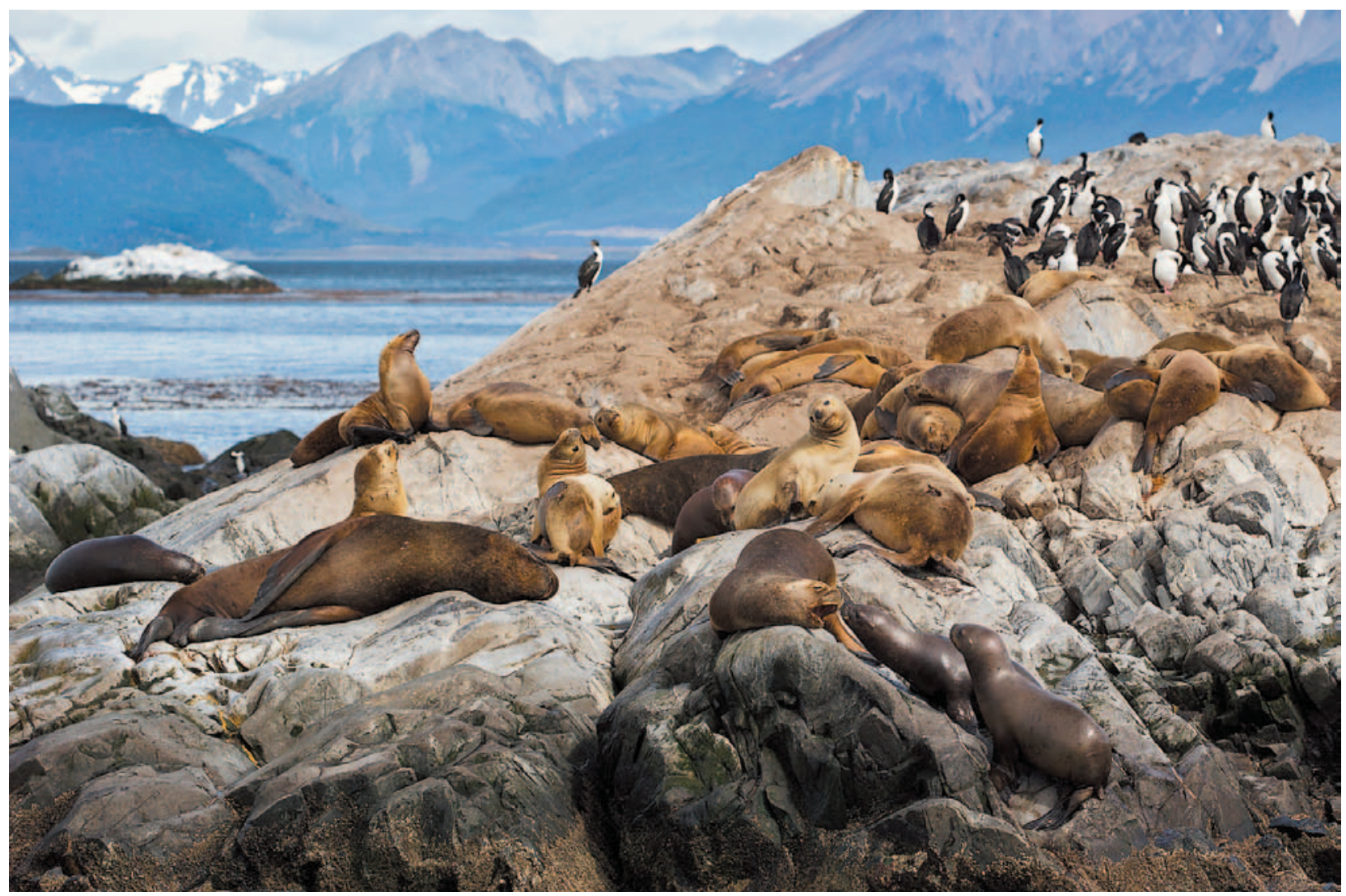

Beagle Channel, Argentina

Albert Knapp, M.D. 